\title{
ECOLOGICAL CHRONOLOGY OF NUCLEAR FUEL CYCLE SITES
}

\author{
MICHAEL BUZINNY, ${ }^{1}$ NIKOLAJ KOVALYUKH, ${ }^{2}$ ILJA LIKHTARJOV, ${ }^{1}$ IVAN LOS, ${ }^{1}$ \\ VALERIJ NESVETAJLO, ${ }^{3}$ MIECZYSEAW F. PAZDUR, ${ }^{4,5}$ VADIM SKRIPKIN, ${ }^{2}$ \\ OLEG SHKVORETS ${ }^{6}$ and EMLEN SOBOTOVICH ${ }^{2}$
}

\begin{abstract}
We compared ${ }^{14} \mathrm{C}$ levels in annual growth rings of pine trees around the Tomsk nuclear fuel reprocessing plant (NFRP) and the Chernobyl nuclear power plant (NPP). At the Chernobyl site, samples were taken from the control area (within a 30-km radius zone around the site) to a distance of $80 \mathrm{~km}$. In Tomsk, we collected samples between 8-10 km and $10-15 \mathrm{~km}$ from the site, taking into account prevailing wind directions. Background samples were collected $200 \mathrm{~km}$ from the plant. Samples were converted to benzene and counted in an ultra-low-level LSC Quantulus $1220^{\mathrm{TM}}$. Because of the Chernobyl accident, a signal can be detected in the background of routine plant operation. Comparison with the Tomsk data suggests that the routine discharges from Tomsk are more significant than the discharge from the Chernobyl accident. We estimated Tomsk NFRP annual discharge level at up to $30-45 \mathrm{TBq}{ }^{14} \mathrm{C}$ from 1985 to 1988.
\end{abstract}

\section{INTRODUCTION}

According to data published by the United Nations (1993), total ${ }^{14} \mathrm{C}$ emissions from the nuclear industry was equivalent to $150 \mathrm{TBq}$ in $1980,360 \mathrm{TBq}$ in $1985,580 \mathrm{TBq}$ in 1990 , and by the year 2000 , will reach almost $1000 \mathrm{TBq}$ (Otlet, Fulker and Walker 1992). Some controversy exists on the contribution of different types of nuclear facilities to total ${ }^{14} \mathrm{C}$ discharges. According to Bush, White and Smith (1983), nearly $70 \%$ of the total ${ }^{14} \mathrm{C}$ discharges in the year 2000 will be from fuel reprocessing. Studies conducted by McCartney and Scott $(1988 \mathrm{a}, \mathrm{b})$ around the Sellafield Nuclear Fuel Reprocessing Plant (NFRP) give figures up to $20 \mathrm{TBq}$ for the annual discharges from the site. We provide details of an analogous study (Kovalykh et al. 1994) around Tomsk, a fuel reprocessing plant situated in western Siberia $\left(57^{\circ} \mathrm{N}\right)$, which has been operating since 1953 , using uraniumgraphite reactors (ADE-4.5). Tree rings were sampled from 8-10 to $10-15 \mathrm{~km}$ southeast and northwest of the plant. We also obtained 1994 data for grass to the southeast. At the same time, a similar study was conducted around the Chernobyl power plant, in which RBMK-1000 reactors were used. The first data relating to ${ }^{14} \mathrm{C}$ releases from Chernobyl were reported by Salonen (1987), although earlier data on tree rings were also published (Buzinny et al. 1992,1993). We sampled pine trees in 1989 and in 1992-1994 within the control area (boundary $30 \mathrm{~km}$ ) and out to $100 \mathrm{~km}$. Background samples were collected over $200 \mathrm{~km}$ from the site. Annual tree rings were sampled from 1979-1993. For the 1986 samples, the rings were split into early and late wood to sensitize detection of any effect from the Chernobyl accident.

\section{METHODS}

The tree-ring samples were given preliminary chemical preparation before counting in proportional (Gliwice) and liquid scintillation (LS) counters (Kiev). Samples for LS were counted in an ultra-lowlevel Quantulus $1220^{\mathrm{TM}}$ counter using PPO and POPOP as scintillators and aluminium Teflon ${ }^{\otimes}$ and copper Teflon $^{\circledast}$ vials. Results were corrected for both fractionation and quenching effects. Oxalic acid was used as the primary standard. Samples of 1986 rings were separated into early and late

\footnotetext{
${ }^{1}$ Department of Dosimetry and Radiation Hygiene, Ukrainian Research Center for Radiation Medicine, Melnikova 53, $254050 \mathrm{Kiev} 50$, Ukraine

${ }^{2}$ Department of Environmental Radiogeochemistry, Ukrainian Academy of Sciences, Palladina 34, 252142 Kiev, Ukraine

${ }^{3}$ Biology and Biophysics Institute of Tomsk State University, Lenin 36, 634050 Tomsk 50 Russia

${ }^{4}$ Department of Radioisotopes, Silesian Technical University, Krzywoustego 2, PL-44-100 Gliwice, Poland

${ }^{5}$ Deceased 11 May 1995

${ }^{6}$ Institute of Radioecology, Ukrainian Academy of Agriculture, Tolstoj 14, 252032 Kiev 32 Ukraine
} 
wood in order to maximize the sensitivity of the method to detect any effect of the Chernobyl accident. More precise steps were also used for some tree-ring samples when both early and late wood were split into two equal parts for the same reason.

\section{RESULTS}

\section{Chernobyl Data}

Figure 1 shows results from the study of long-term variations in one tree, as well as the 1986 result for three other trees located at distance of 2.4 and $4 \mathrm{~km}$ from the site. The long-term trend from $1965-1978$ is very similar to the global ${ }^{14} \mathrm{C}$ levels in the atmosphere. The data from $1979-1985$ and 1987-1989 show elevated levels corresponding to the operational activity of the plant. The results for 1986 give specific activities in the range from 720 to $6533 \mathrm{~Bq} \mathrm{~kg}^{-1}$, and show a high degree of local spatial variation.

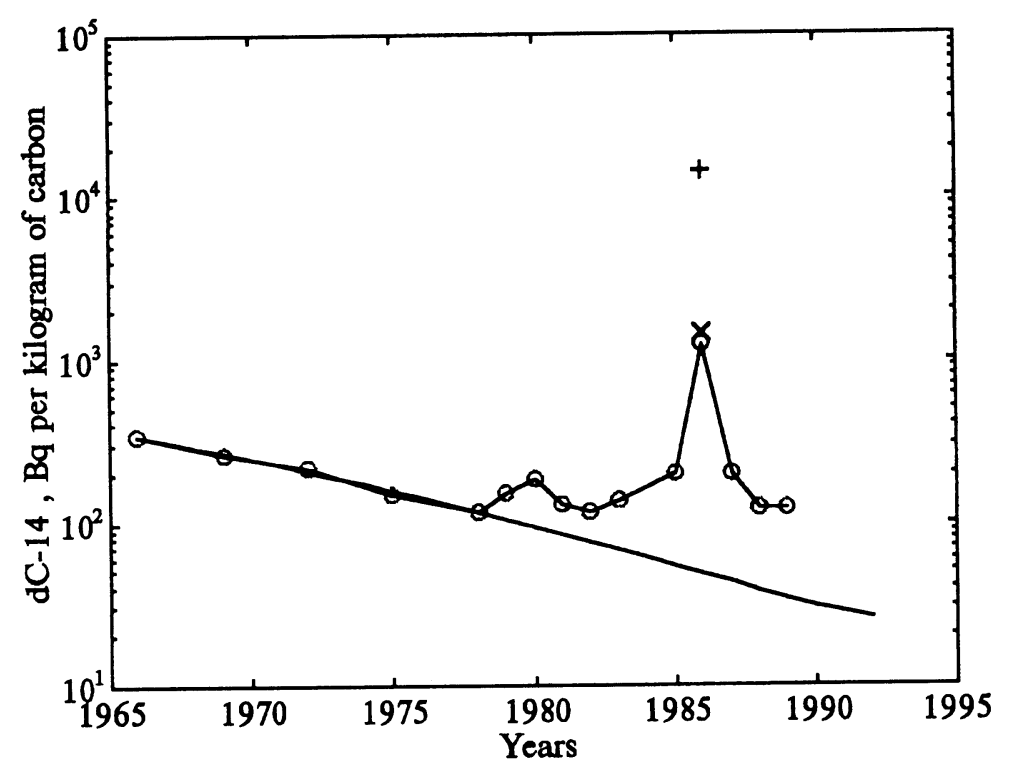

Fig. $1 .{ }^{14} \mathrm{C}$ specific activity in pine tree rings collected near Chernobyl NPP, Bq kg-1 C (Buzinny et al. 1992). + = "Red Forest", 4 km W-N; X = "Red Forest", $2.5 \mathrm{~km} \mathrm{W;} 0$ = "Red Forest", 6 km W-S; - = extrapolation of years 1966-1978.

For subsequent sampling around Chernobyl, we used an aerial survey of gamma radiation. The background sample was obtained $200 \mathrm{~km}$ south of Chernobyl. Table 1 shows the 1986 results for trees around Chernobyl as well as for background samples. There is significant variation in ${ }^{14} \mathrm{C}$ level over the samples; thus, we developed an optimized sample preparation method in which the early and late wood are separated for some of the trees. The samples were then split in half. We believe this procedure may increase the detection of excess ${ }^{14} \mathrm{C}$ (Table 2).

We determined the maximum ${ }^{14} \mathrm{C}$ level in samples collected $4 \mathrm{~km}$ northwest of Chernobyl, corresponding to the specific activity of $6500 \mathrm{~Bq} \mathrm{~kg}^{-1} \mathrm{C}$. We estimated the average ${ }^{14} \mathrm{C}$ concentration in air during the release to be $50 \mathrm{~Bq} \mathrm{~m}^{3}$ (averaged over a 14-day discharge period). This figure is subject to variation due to changes in wind direction and weather conditions; thus, it is not unreasonable 
to hypothesize maximum levels to be 100-1000 times higher than the mean level. Table 1 clearly shows considerable local variation in ${ }^{14} \mathrm{C}$ levels, and that increased sensitivity has been obtained through our sampling method. It is reasonable to assume other discharges may behave like $\mathrm{CO}_{2}$. Therefore, the use of this method for reconstructing past discharges seems possible, something we are currently examining.

TABLE $1 .{ }^{14} \mathrm{C}$ concentration in 1986 annual tree-ring samples collected around Chernobyl NPP. Uncertainty is $c a .3 .5 \mathrm{~Bq} \mathrm{~kg}^{-1} \mathrm{C}$ for early and late wood samples, $c a$. $3 \%$ for other samples.

\begin{tabular}{lllrccc}
\hline No. & Site & Direction & $\begin{array}{c}\text { Distance } \\
(\mathrm{km})\end{array}$ & 1986 & $\begin{array}{c}1986 \\
(\mathrm{E}){ }^{*}\end{array}$ & $\begin{array}{c}1986 \\
(\mathrm{~L}) \dagger\end{array}$ \\
\hline 1 & "Red Forest" & NW & 4.0 & 857.0 & - & - \\
2 & Tree nursery & W & 2.5 & 6533.0 & - & - \\
3 & Leljev & SW & 6.0 & 720.0 & - & - \\
4 & Paryshev & SE & 10.0 & 327.0 & 350.7 & 303.3 \\
5 & Sachan & N & 12.0 & 308.6 & 345.5 & 271.2 \\
6 & Janov & W & 2.0 & $9700.0(\mathrm{E})$ & $17,130.0(1) \ddagger$ & $302.5(2) \ddagger$ \\
7 & Janov & W & 2.0 & $302.1(\mathrm{~L})$ & $305.0(1)$ & $300.2(2)$ \\
8 & Tarastcha§ & S & 200.0 & $272.6(\mathrm{E})$ & $274.3(1)$ & $270.8(2)$ \\
9 & Tarastcha & S & 200.0 & $268.7(\mathrm{~L})$ & $268.2(1)$ & $269.2(2)$ \\
\hline "Early wood & & & & &
\end{tabular}

†Late wood

$¥ 1$ or 2 indicates early and late wood were divided into two equal parts in the order L1, L2, E1, E2

$\S$ Tarastcha $=$ background sample

TABLE 2. Excessive ${ }^{14} \mathrm{C}(\mathrm{Bq} \mathrm{kg}-1 \mathrm{C}$ above natural level $)$ in annual rings of trees around nuclear reprocessing plant Tomsk-7, Russia Tomsk samples $=10 \mathrm{~km} \mathrm{NE}$; Tomsk 2 samples $=10-15 \mathrm{~km} \mathrm{SW}$.

\begin{tabular}{rr|rcc|rcr|rcc}
\hline Year & Tomsk & Year & Tomsk & Tomsk 2 & Year & Tomsk & Tomsk 2 & Year & Tomsk & Tomsk 2 \\
\hline 1949 & -6.6 & 1961 & 113.0 & -- & 1973 & 143.7 & 101.7 & 1984 & 155.5 & 64.9 \\
1950 & 2.7 & 1962 & 128.3 & -- & 1974 & 147.6 & 101.2 & 1985 & 173.2 & 57.7 \\
1951 & -3.9 & 1963 & 198.6 & -- & 1975 & 154.8 & 89.0 & 1986 & 167.5 & 62.7 \\
1952 & 2.3 & 1964 & 239.3 & -- & 1976 & 159.1 & 109.6 & 1987 & 160.9 & 56.8 \\
1953 & 5.4 & 1965 & 245.4 & -- & 1977 & 149.8 & 90.8 & 1988 & 171.8 & 56.5 \\
1954 & 14.8 & 1966 & 221.3 & -- & 1978 & 153.7 & 81.9 & 1989 & 163.2 & -- \\
1955 & 13.4 & 1967 & 200.0 & -- & 1978 & 153.7 & 81.9 & 1990 & 160.7 & -- \\
1956 & 16.6 & 1968 & 170.7 & -- & 1979 & 168.7 & 67.6 & 1991 & 157.1 & -- \\
1957 & 37.5 & 1969 & 146.9 & 129.4 & 1980 & 177.1 & 75.6 & 1992 & 153.0 & - \\
1958 & 49.0 & 1970 & 153.0 & 126.2 & 1981 & 164.6 & 67.0 & 1993 & 115.3 & -- \\
1959 & 76.5 & 1971 & 143.5 & 121.0 & 1982 & 157.3 & 75.6 & & & \\
1960 & 92.2 & 1972 & 155.9 & 113.5 & 1983 & 145.1 & 55.6 & & & \\
\hline
\end{tabular}

\section{Tomsk-7 Data}

We determined the variability in ${ }^{14} \mathrm{C}$-specific activity in tree rings and in the atmosphere at the Tomsk site from 1953-1993. The Tomsk results can be compared to other atmospheric data (Kaimei, Youneng and Fan 1992) for a background site. Both data series are shown in Figure 2. At Tomsk-7, the ${ }^{14} \mathrm{C}$ discharges have been increasing since 1970 and have resulted in a ${ }^{14} \mathrm{C}$ level exceeding $120 \mathrm{~Bq} \mathrm{~kg}^{-1} \mathrm{C}$ in the tree rings $10 \mathrm{~km}$ from the site. The 1993 data show evidence of a decrease in ${ }^{14} \mathrm{C}$ discharges. 
We have also employed the data to determine the discharge levels retrospectively, using the data of $\mathrm{McC}$ artney and Scott $(1988 \mathrm{a}, \mathrm{b})$ to determine a coefficient relating excess ${ }^{14} \mathrm{C}$ in the tree rings to discharge. Our justification for this is that the spatial distribution of the site is similar to Sellafield (e.g., in $1985,20-30 \mathrm{~Bq} \mathrm{~kg}^{-1} \mathrm{C}$, corresponding to a discharge of $7 \mathrm{TBq}$ ). Using this approach, we estimate the coefficient to be $0.23-0.35 \mathrm{TBq} \mathrm{a}^{-1} \mathrm{~Bq}^{-1} \mathrm{~kg}$. In the future, more experimental work will be carried out to define exact spatial distribution for the site. Using this coefficient, we estimate the highest Tomsk discharge at 1.5-2.5 times higher (Fig. 3) than the relative ${ }^{14} \mathrm{C}$ maximum at Sellafield in 1981. We estimate maximum annual discharges to be $31 \mathrm{TBq} \mathrm{a}^{-1}$ in 1988 and the total discharge during the operational period to be $450-620 \mathrm{TBq}$.

1994 grass samples collected at 5-6 km southwest (wind direction) yield an excessive ${ }^{14} \mathrm{C}$ level of $54.9 \pm 4.6\left(\mathrm{~Bq} \mathrm{~kg}^{-1} \mathrm{C}\right.$ above natural level). This establishes a decrease in the level of ${ }^{14} \mathrm{C}$ discharges since 1993 (compare the 1988 value of $56.5 \mathrm{~Bq} \mathrm{~kg}^{-1}$ at $15 \mathrm{~km}$ southeast of T2).

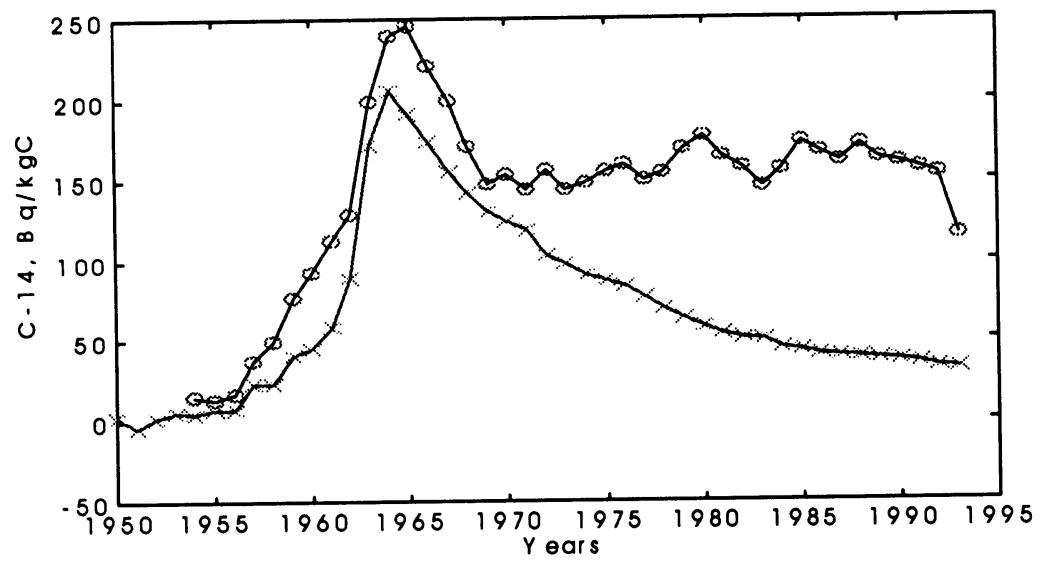

Fig. $2 .{ }^{14} \mathrm{C}$ concentration (o) of annual pine tree rings $(\mathrm{Bq} \mathrm{kg}-1 \mathrm{C})$ around the Tomsk-7 nuclear reprocessing plant (Russia), relative to background. Pre-1950 AO background taken as 0 . The bomb ${ }^{14} \mathrm{C}$ curve $(x)$ is also shown from a background site (Kaimei et al. 1992).

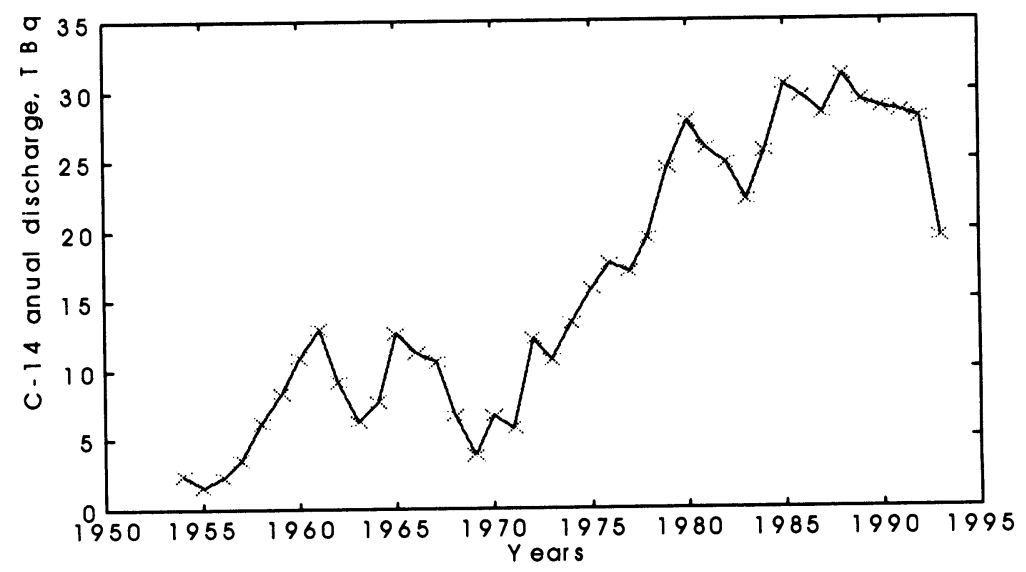

Fig. 3. Reconstructed annual ${ }^{14} \mathrm{C}$ discharges for Tomsk (details in text) 


\section{CONCLUSION}

We conclude that, using the methodology described above, we can determine excess ${ }^{14} \mathrm{C}$ levels to at least $30 \mathrm{~km}$ from the Chernobyl site, and can extend our study area to other sites on a wider scale. At both Tomsk and Chernobyl, effects of the ${ }^{14} \mathrm{C}$ discharges are local and spatially varied. The comparison of Tomsk and Chernobyl shows that routine releases at Tomsk are more significant than those at Chernobyl. However, as a result of the accident at Chernobyl, and taking into account wind direction and weather variation, the maximum ${ }^{14} \mathrm{C}$ atmospheric concentration was $100-1000$ times higher than the average level of $50 \mathrm{~Bq} \mathrm{~m}^{-3}$. These high levels are found in the early wood of 1986 tree rings. Because the behavior of other gases is similar to that of $\mathrm{CO}_{2}$ discharged during the accident, we should also be able to reconstruct and make a radiological assessment of the discharge levels of those gases. We are planning further studies to provide more detail about the distribution of excess ${ }^{14} \mathrm{C}$ around Chernobyl and to establish discharge records for both sites.

\section{ACKNOWLEDGMENTS}

We are grateful to the Ukrainian Ministry of Chernobyl for partial support of the study, and M. B. is grateful to the British Council for funding his participation in the 15th International Radiocarbon Conference.

\section{REFERENCES}

Bush, R. P., White, I. F. and Smith, G. M. 1983 Carbon14 Waste Management. AERE-R10543.

Buzinny, M., Zelensky, A., Kovalyukh, N., Skripkin, V. and Sanin, E. 1993 Retrospective reconstruction of C14 levels in the emergency explosion after the Chernobyl accident. In The Conference on Current Questions of Retrospection, Running and Prediction Radiation Dosimetry after the Chernobyl Accident. Kiev, 27-29 October 1992. Ukrainian Scientific Center of Radiation Medicine, Enterprise "ROSA" MinChernobyl of Ukraine: 118-124 (in Russian).

Buzinny, M. G., Los, I., Zelensky, A.V., Kovaljukh, N. N. and Skripkin, V. V. 1993 Possible correlation of the ${ }^{14} \mathrm{C}$ level in vegetables and ${ }^{131} \mathrm{I}$ in the thyroid gland due to the Chernobyl accident: Current problems of resolving medical consequences of the Chernobyl accident. In Abstracts of Ukrainian Scientific Practical Conference, Part I. Kiev, 20-22 April 1993. Health Ministry of Ukraine, Ukrainian Center for Radiation Medicine: 48-49 (in Russian).

Kaimei, D., Youneng, Q. and Fan, C. Y. 1992 Bomb-produced ${ }^{14} \mathrm{C}$ in tree rings. In Long, A. and $\mathrm{Kra}, \mathrm{R}$. S., eds., Proceedings of the 14th International ${ }^{14} \mathrm{C}$ Conference. Radiocarbon 34(3): 753-756.

Kovalyukh, N., Skripkin, V., Awsiuk, R., Pazdur, M., Pazdur, A., Los, I., Buzinny, M. and Nesvetajlo, V.
1994 Dendroradioecology of the vicinity of the nuclear fuel reprocessing plant Tomsk-7. Extended $A b$ stracts, International Isotope Society, University of Wroclaw. Isotope Workshop II, 25-27 May 1994: 8385.

McCartney, M. and Scott, E. M. 1988a Carbon-14 discharges from the nuclear fuel cycle: Global effects. Journal of Environmental Radioactivity 8(1): 143155.

1988b Carbon-14 discharges from the nuclear fuel cycle: Local effects. Journal of Environmental Radioactivity 8(2): 157-171.

Otlet, R. L., Fulker, M. J. and Walker, A. J. 1992 Environmental impact of atmospheric carbon-14 emissions resulting from the nuclear energy cycle. In Taylor, $\mathbf{R}$. E., Long, A. and Kra, R. S., eds. Radiocarbon After Four Decades: An Interdisciplinary Perspective. New York, Springer Verlag: 519-534.

Salonen, L. 1987 Carbon-14 and tritium in air in Finland after the Chernobyl accident. Radiochimica Acta 41: 145-148.

United Nations Scientific Committee on the Effects of Atomic Radiation (UNSCEAR) 1993 Sources and Effects of Ionizing Radiation. Report to the General Assembly, with Scientific Annexes. New York, United Nations: 922 p. 